\title{
Assessment of Drought Vulnerability and Occurrence Zones in North Central Nigeria
}

\author{
Oye Ideki ${ }^{*}$, Vincent E. Weli ${ }^{2}$ \\ ${ }^{1}$ Department of Meteorology and Climate Change, Nigeria Maritime University, Okerenkoko, Nigeria \\ ${ }^{2}$ Department of Geography and Environmental Management, University of Port Harcourt, Port Harcourt, Nigeria \\ Email: *oyelistic@yahoo.com
}

How to cite this paper: Ideki, O. and Weli, V.E. (2019) Assessment of Drought Vulnerability and Occurrence Zones in North Central Nigeria. Atmospheric and Climate Sciences, 9, 298-309.

https://doi.org/10.4236/acs.2019.93021

Received: April 4, 2019

Accepted: June 14, 2019

Published: June 17, 2019

Copyright (c) 2019 by author(s) and Scientific Research Publishing Inc. This work is licensed under the Creative Commons Attribution International License (CC BY 4.0).

http://creativecommons.org/licenses/by/4.0/

\section{cc) (i) Open Access}

\begin{abstract}
Assessment of drought vulnerability and occurrence zones in North Central Nigeria was carried out in this study using standardized Precipitation Index (SPI). The Standardized Precipitation Index (SPI) 12 months' time scale was computed from long-term rainfall data between 1960 and 2015 obtained from the Nigerian Meteorological Agency (NIMET) Abuja. The SPI results were further subjected to Mann-Kendal and Sen's slope analysis for trend detection. To assess the vulnerability of drought and occurrence zones, the SPI and other geo-spatial techniques were employed to generate drought vulnerability maps for three epochs: 2000-2005, 2005-2010 and 2010-2015 respectively. The SPI values were interpolated using Inverse Weighted (IDW) techniques in ArcGIS10.5 to generate the vulnerability maps for the selected model years. The outcome of drought trend and vulnerability maps reveals increasing drought trend dominated by near normal and moderate conditions in Abuja, Ilorin and Lokoja while moderate and severe droughts were observed in Minna and Jos. The study therefore recommends holistic drought monitoring and management strategies in order to mitigate its adverse impact on water resources and rainfall-dependent agriculture.
\end{abstract}

\section{Keywords}

Drought, Vulnerability, Rainfall, Standardized Precipitation Index (SPI),

Occurrence Zones, North Central, Nigeria

\section{Introduction}

Drought is a devastating disaster that is known globally due to its subtle effects on agriculture, forestry, vegetation and human economic activities [1]. The agro-industry is severely affected by drought as vegetation and plants suffer the 
deficiency of water in the air and soil in the process of evapotranspiration [2]. To this end, the importance of rainfall as a critical determinant of drought and the climate system cannot be overemphasized. For effective conceptualization of the subject matter, it therefore becomes imperative that drought should be comprehensively investigated for proper and efficient understanding of its characteristics and vulnerability especially in North Central Nigeria [3].

The variability of rainfall in terms of duration, amount and intensity in the Northern part of Nigeria has resulted in dryness and rainfall is below the normal proportion to support crop production and livelihood. The characteristics of rainfall as examined in Nigeria [3] revealed a progressive retreat in the North Central States. Furthermore, there is evidence of a rapid downward trend of rainfall in North Central states among which are Minna, Jos, Lokoja and Ilorin [4]. The observed decreasing trend in rainfall with delayed onset and early cessation has enormous implications on drought in the region.

The 2017 and 2018 seasonal rainfall prediction (SPR) by Nigeria Meteorological Agency [5] [6] [7] indicates that most of the North Central states such as Niger, Plateau and Nassarawa were predicted to have late onset and early cessation. However, in 2017, while $1545 \mathrm{~mm}$ and $1240 \mathrm{~mm}$ of rainfall were predicted over Ilorin and Minna, the actual amount of rainfall recorded was 1324 and 1050 respectively. The prediction for temperature was not different as the agency warned that most parts of the North including the central states were expected to experience warmer than normal temperatures. Evidence in literature indicates that rainfall variability in the North Central region has been reported in retrospect [8]. The report which analyzed rainfall data from 1911-2000 under 30 years interval of 1911-1940, 1941-1970 and 1971-2000 revealed that parts of the Central states are recording late onset of rainfall, early cessation and shortened length of the rainy season and a reduction in the amount of rainfall. The author further observed that drought frequency, persistent harm than a haze and increasing trend of temperature are signposts that North Central Nigeria remains vulnerable to drought risk. In addition, the declining rainfall trend results in insufficient moisture availability required for optimum plant growth and development. The early cessation of rainfall will also create water stress conditions and represent clear evidence of the region's vulnerability to drought.

Studies of desert encroachment as an evidence of drought in the North Central region are well documented [9]. In the same vein, [10] established that the desert which were initially restricted to the Sudano-Sahelian region is fast spreading to Niger, Plateau and Benue States. The rate of advancement of the desert has been put at an estimated $0.6 \mathrm{~km}$ per annum while deforestation is taking place at $3.5 \%$ annually [11]. The rate of desert encroachment signpost declining rainfall and vegetation cover which implies a reduction in the amount of surface water available especially in rural areas. These climatic anomalies have also been reported by [12], which affirmed that water shortages remain a recurrent environmental challenge in Benue State. Furthermore, the soil in many parts of the region is drying up and vegetation health is in great danger as a re- 
sult of increased temperature and reduced rainfall.

Although, drought has extensively been studied in Nigeria, unfortunately most of the studies are concentrated in the Sahelian regions of the country with little or no effort to investigate drought characteristics in the study area. It is in view of the foregoing, that this study was carried out to assess drought vulnerability and occurrence zone in North Central Nigeria.

\section{Materials and Methods}

\subsection{The Study Area}

North Central Nigeria lies approximately between $3^{\circ}$ and $14^{\circ} \mathrm{E}$ and latitude $7^{\circ}$ and $10^{\circ} \mathrm{N}$ [13]. The region is made up of six states namely Benue, Kwara, Niger, Plateau, Nassarawa, Kogi and Abuja (Figure 1). The relief of the lower Benue basin comprises of two distinctive relief regions. The area has network of drainage system forming tributaries that flow from the Benue River and River Niger. At Lokoja, the River Niger and Benue meet to form a confluence. Greater part of the region is drained by the Benue River extension. The North Central region is mainly influenced by the climate of the northern and southern regions of Nigeria. The study area is within the Guinea Savannah vegetation belt with deciduous trees comprising grasses and shrubs [14]. The soil is generally characterized by a sandy surface horizon overlying a weak structured clay accumulation. The Geology of the lower Benue basin is underlain by two principal geological formations namely the Precambrian basement complex and the sedimentary formation [13]. The Federal Capital Territory (FCT) created in 1976 is the head of administration and political activities in the region. Agriculture forms the backbone of the economy of the lower Benue basin with more than $70 \%$ of the

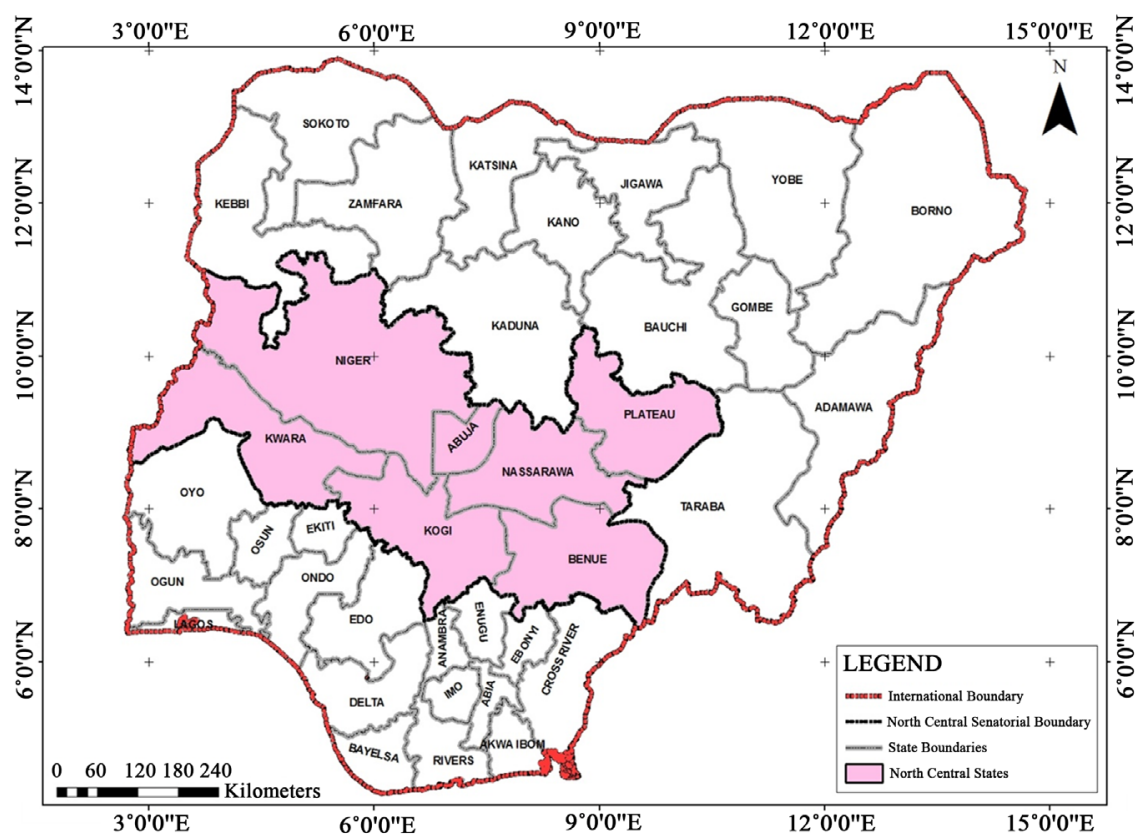

Figure 1. North central Nigeria, Source: (Authors field work, 2019). 
working population engaged in farming, fishing, livestock and poultry making the region the food basket of the country.

\subsection{Standardized Precipitation Index (SPI)}

The Standardized Precipitation Index (SPI) was applied to determine the intensity and occurrence of drought. The model was developed by [15] and uses only rainfall in the computation.

The SPI formula is as follows:

$$
\mathrm{SPI}=\frac{X_{i j}-\bar{X}_{i}}{\sigma_{i}}
$$

where: $X_{i j}$ is the rainfall for the $i$ th and $j$ th station observations. $\bar{X}_{i}$ is the mean rainfall for the $i$ th station an $\sigma_{i}$ is the standard deviation for the $i$ th station.

The SPI drought classification table that is shown in Table 1, was applied to access possible drought occurrence in each of the stations that constitutes the study area. SPI values can be positive or negative. Negative SPI value indicates drought occurrence while positive values shows no drought.

SPI 12 month time scale was used in each station to evaluate the risk of drought in the seven meteorological stations of the study area. The 12 month SPI represents annual and accumulated drought. It is also tied to stream flows and reservoir levels. Increasing SPI implies, increasing drought condition and vice versa [1] [7].

\section{Results and Discussion}

\subsection{Rainfall Variation}

The analysis of rainfall in the study area is presented in Table 2. The table reveals a temporal variation in rainfall over the 56 years (1960-2017) study period collected from [16]. It indicates that there is statistical significant difference in annual rainfall amount in the area between 1960 and 2017 since between groups variation is greater than the within group variation of the data set.

Table 1. SPI classification table.

\begin{tabular}{cc}
\hline SPI & Drought event \\
\hline $2.0+$ & Extremely wet \\
$1.5-1.99$ & Very wet \\
$1.0-1.49$ & Moderately wet \\
$-0.99-0.99$ & Near normal \\
$-0.1-1.49$ & Moderately dry \\
$-1.5-1.99$ & Severely dry \\
-2 and less & Extremely dry \\
\hline
\end{tabular}

Source: [15]. 
Table 2. ANOVA result showing spatial variation in rainfall.

\begin{tabular}{cccccc}
\hline & Sum of Squares & Df & Mean Square & F & Sig. \\
\hline Between Groups & $409,841.699$ & 6 & $68,306.950$ & 5.839 & 0.000 \\
Within Groups & $5.000 \mathrm{E} 7$ & 4688 & $11,698.639$ & & \\
Total & $5.041 \mathrm{E} 7$ & 4704 & & & \\
\hline
\end{tabular}

Data Source: [16]. Df = Degree of Freedom; F = F-calculated value (Used in an F-distribution data when comparing statistical means using the least square model to show variance). Sig = Significance level used in an SPSS analysis. It's also known as P Value.

The F-calculated value of 5.839 is statistically significant $(\mathrm{P}<0.05)$ at $95 \%$ confidence level. The application of the Duncan Post hoc test on the difference between rainfall total of the study is shown in Table 3. Abuja had mean value of 94.8565 indicating that there is significant difference in annual rainfall between Abuja and the other states in the area.

The table reveals that Abuja was distinct from the other states in terms of difference in her mean value (94.8565). This indicates that there is statistical difference in annual rainfall totals between Abuja and the other states in the study area.

\subsection{Drought Trend Analysis}

The result of MannKendall analysis shown in Table 4 indicates negative $Z$ values for Makurdi (Benue State), Ilorin (Kwara State), Minna (Niger state) and Jos (Plateau state). The result reveals that the aforementioned stations experienced drought of SPI 12 month's time scale implying increasing drought trend.

The Sen's slope values indicate the magnitude of change in the drought trend. The magnitude of change was highest in Jos, followed by Markurdi and Ilorin respectively. Although, the Z-scores for Abuja and Lafia were positive, they were generally significant at 0.5 and 0.01 confidence level. This could impact negatively on water resources and the rainfall dependent agriculture [6] [17].

\subsection{Drought Occurrence and Vulnerability Assessment in North Central Nigeria}

The SPI analysis was carried out to assess the trend, vulnerability and occurrence of drought in each of the meteorological station by applying the 12 months' time scale. The outcome of the analysis is in agreement with previous studies on drought risk assessment in Nigeria [7] [8] [18] [19] [20].

The result of 12 months SPI time scale as shown in Figure 2 reveals that drought of different intensities occurred in 1986, 1970, 1974, 1982, 1986, 1994, 2002 and 2008. The implication of this analysis is that Makurdi is vulnerable and remains high in the drought occurrence map.

The outcome of the 12 month SPI analysis for Ilorin shown in Figure 3 below confirmed the following years: 1960, 1966, 1970, 1976, 1988, 1992, 1996, 2010 and 2012 as periods of severe drought implying high risk while year 2000 


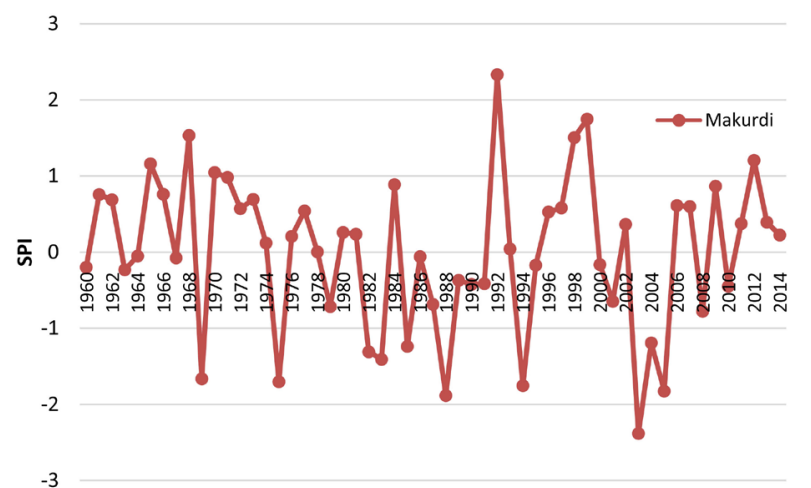

Figure 2. SPI 12 month time scale for Markurdi.

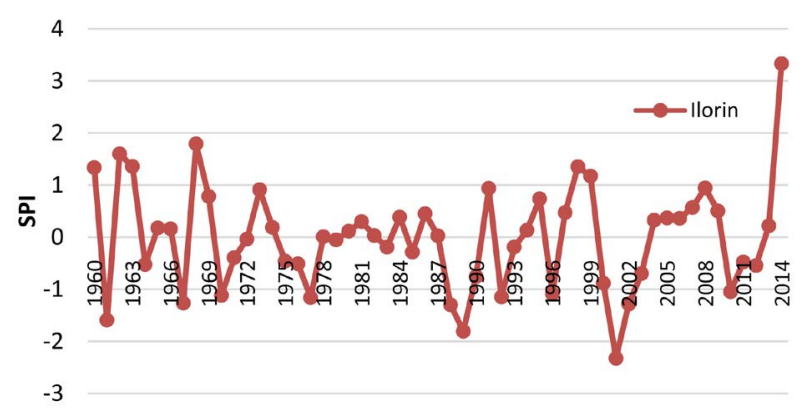

Figure 3. SPI 12 month time scale for Ilorin.

Table 3. Result of Duncan post hoc test.

\begin{tabular}{ccccc}
\hline \multirow{2}{*}{ Indicators } & $\mathrm{N}$ & \multicolumn{3}{c}{ Subset for alpha $=0.05$} \\
\cline { 3 - 5 } & & 94.8565 & 2 & 3 \\
\hline Abuja & 684 & & 100.4253 & \\
Lafia & 684 & 100.7753 & \\
Ilorin & 684 & 101.0670 & \\
Lokoja & 684 & & 3387 \\
Markurdi & 684 & & & 102.9477 \\
Minna & 684 & & & 106.7314 \\
Jos & 684 & & & 0.890 \\
Sig. & & 1.000 & 0.874 & \\
\hline
\end{tabular}

Means for groups in homogenous subsets are displayed. a: Uses Harmonic Mean Sample Size $=684$.

Table 4. Mann Kendall and Sen's slope analysis using SPI 12 month scale.

\begin{tabular}{ccc}
\hline Station & Mann Kendall $(\mathrm{Z})$ values & Sen slope estimate $(\mathrm{Q})$ values \\
\hline Makurdi & -1.01 & -0.008 \\
Ilorin & -0.22 & -0.002 \\
Lokoja & 0.33 & 0.002 \\
Minna & -0.01 & 0.000 \\
Jos & $-1.70^{+}$ & -0.013 \\
Abuja & $2.08^{*}$ & 0.037 \\
Lafia & $2.75^{* *}$ & 0.171 \\
\hline
\end{tabular}

${ }^{* * *}$ if trend at $\alpha=0.001$ level of significance; ${ }^{*}$ if trend at $\alpha=0.01$ level of significance; ${ }^{*}$ if trend at $\alpha=0.05$ level of significance; ${ }^{+}$if trend at $\alpha=0.1$ level of significance. 
represents extreme drought hence, the station can be described as highly vulnerable to the incidence of drought.

The result of the SPI analysis shown in Figure 4 below reveal drought event of different intensities was experienced in Lokoja. While 1972 and 1976 are indicative of moderate drought, severe drought occurred in 1980 and 1984.The time series analysis also revealed that, the station experienced below rainfall in 1972, 1974, 1980, 1984 as well as 1998, and 2004 before reaching its peak in 2010.

It is evident from the results of the analysis presented in Figure 5 below, that Minna is highly vulnerable to drought risk. This vulnerability might be further aggravated by future rainfall declines as reported by several research findings. In their findings, they claimed that climate change is creating shifts in rainfall patterns [21]. There are wide implications for this as it could affect the sustainability of surface and ground water resources to meet up essential needs.

In Jos as shown in Figure 6, extreme drought occurred in 1960, 1996, 1994, 2004 and 2012 respectively as revealed by the risk matrix. Furthermore, severe

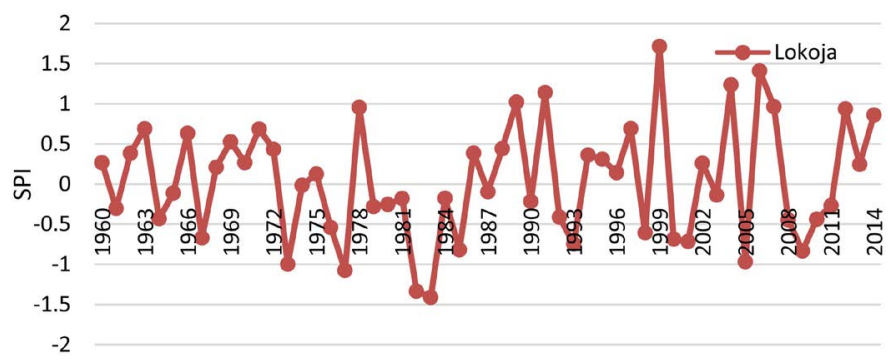

Figure 4. SPI 12 month time scale of drought analysis for Lokoja.

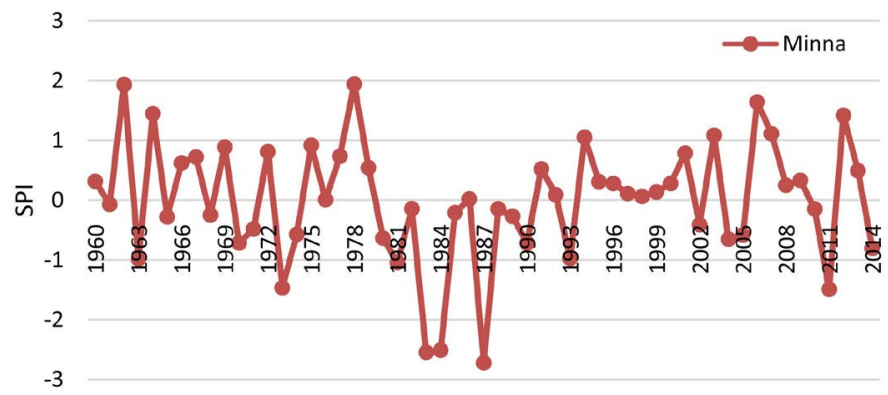

Figure 5. SPI 12 month time scale of drought analysis for Minna.

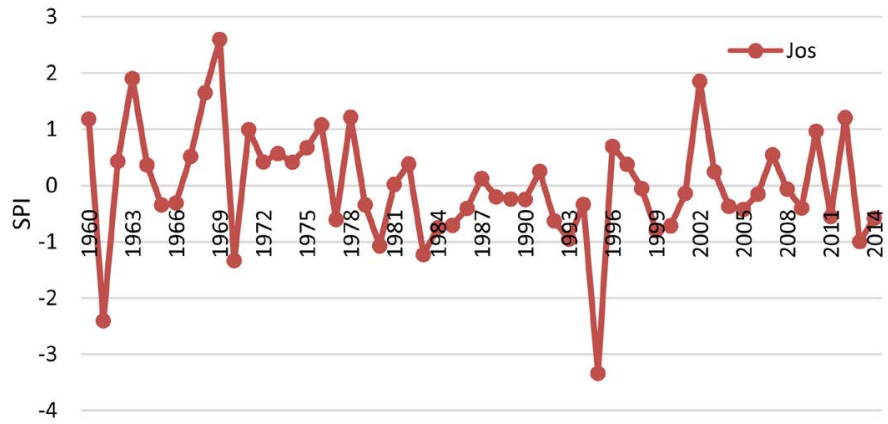

Figure 6. SPI 12 month time scale of drought analysis for Jos. 
drought occurred in 1962, 1970, 1980, 1982, 1986, 1988, 1992, and 1998 and more recently in 2000, 2004 and 2014. The results affirm that the aforementioned years were generally dry in Jos. This is an indication of drought vulnerability given that the station experienced decreasing rainfall trend with attendant impact on agriculture and socio-economic activities.

Lafia was only affected by drought event of moderate category in 2001, 2004, 2007 and 2010 as shown in Figure 7. This implies that Lafia is relatively low in terms of drought risk and vulnerability compared to other stations such as Minna and Jos. It was also observed that 2001 and 2004 marked a period of sustained dryness which extended from 2007 to 2010. The result further reveals that rainfall improved considerably in the station as the wet season was at its peak in 2010.

The analysis of the 12 month SPI for Abuja is shown in Figure 8 below. The result reveals that moderate drought occurred in 1984, 1988, 1990, 1996, 1998 and 2012 respectively while severe drought was noticed in 2000, 2002 and 2008. This could be devastating for farmers in the Federal Capital Territory (FCT) as crop yielded was severely affected.

\subsection{SPI Generated Drought Vulnerability Map}

This section deals with presentation of SPI generated spatial maps of three different intervals. The maps were generated to show the risk level and vulnerability

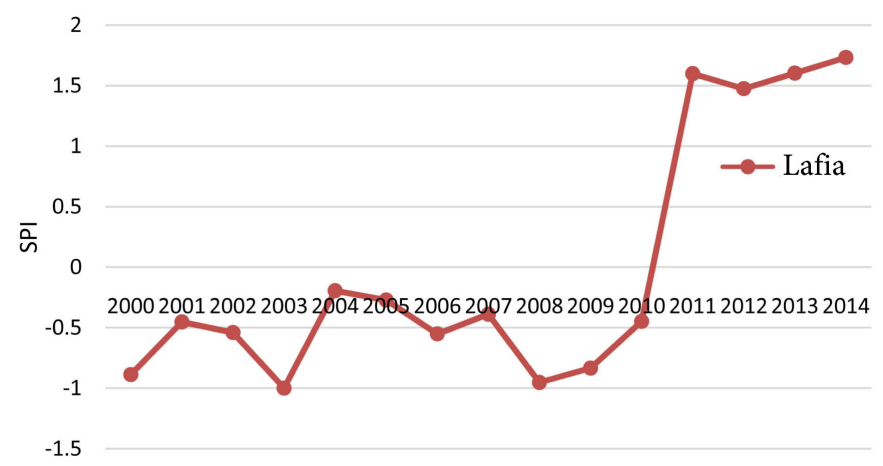

Figure 7. SPI 12 month time scale of drought analysis for Lafia.

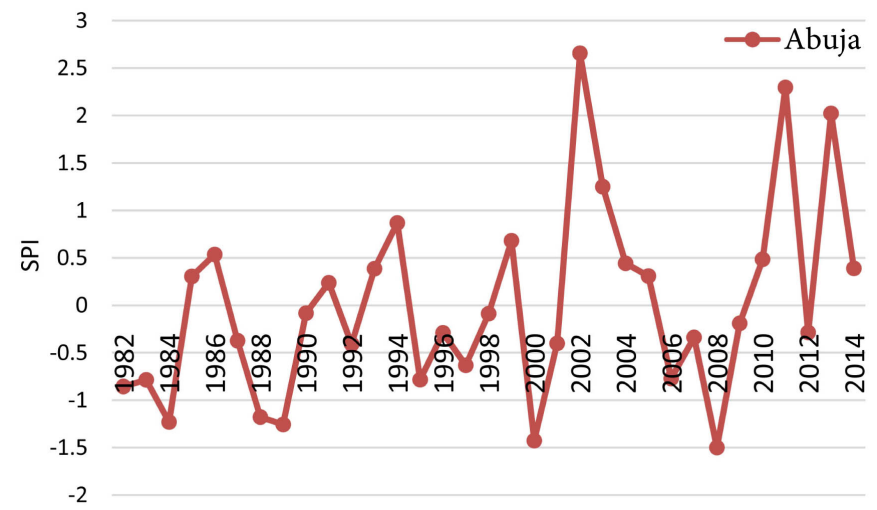

Figure 8. SPI 12 month time scale of drought analysis for Abuja. 
of each station to drought. It further indicates the pattern of drought occurrence in the study area using an interval of five years namely 2000-2005, 2005-2010, and 2010-2015.

The drought risk map for the first interval of 2000-2005 in Figure 9 indicates that drought vulnerability was low in all the stations as the SPI values were all positive. This implies that the period was characterized by improved rainfall in the study area.

The 2000-2005 vulnerability map as shown in Figure 9 was characterized by low risk level particularly in the Northern axis of Abuja, Plateau and Nasarawa states as indicated by the SPI negative values.

The result of the analysis agrees with studies undertaken by [1] [9] [18] [20] [21] [22] and [23] on drought risk assessment and vulnerability.

The 2005-2010 vulnerability map as shown in Figure 10 is characterized by high risk implying severe and extreme drought intensities in the central part of the study area. This is followed by moderate drought condition in the central, eastern and southern part of the region.

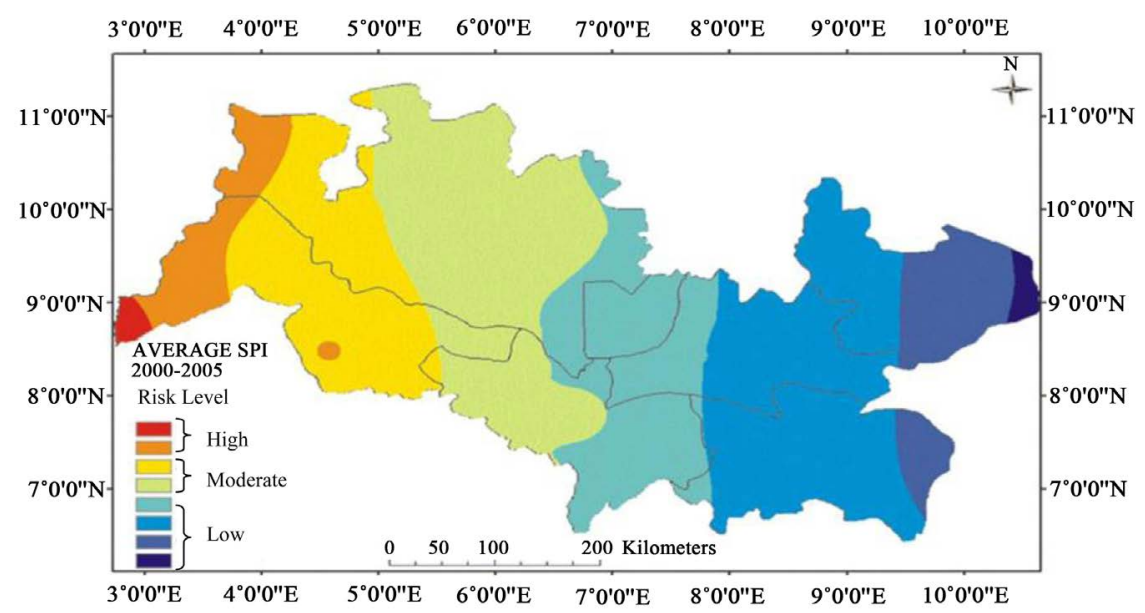

Figure 9. Drought vulnerability map of 2000-2005.

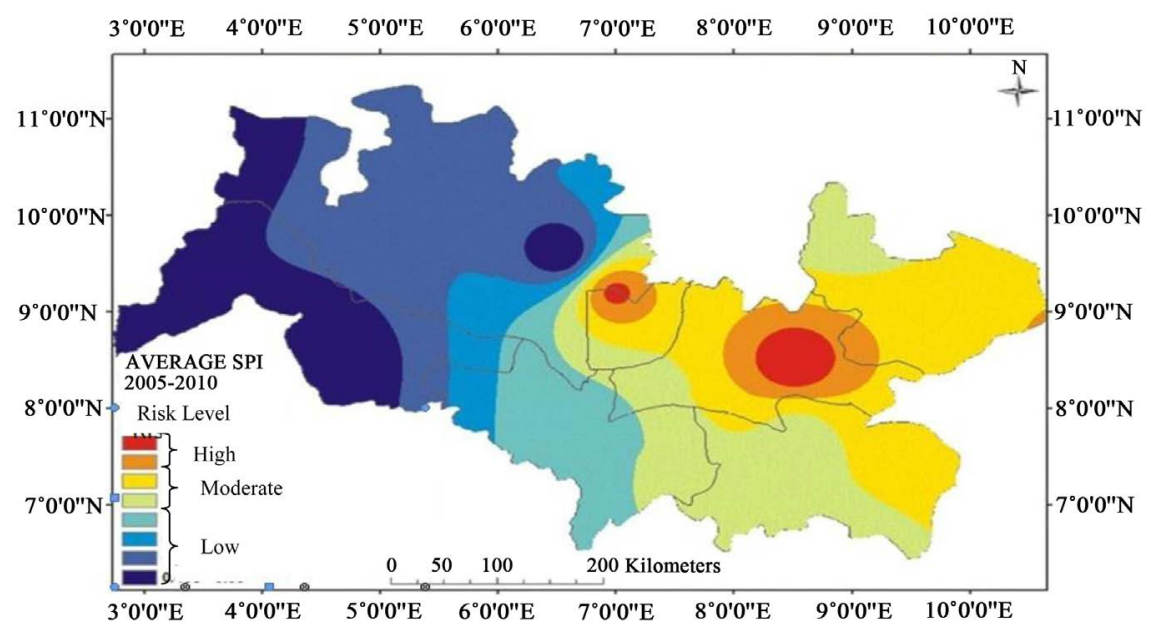

Figure 10. Drought vulnerability map of 2005-2010. 


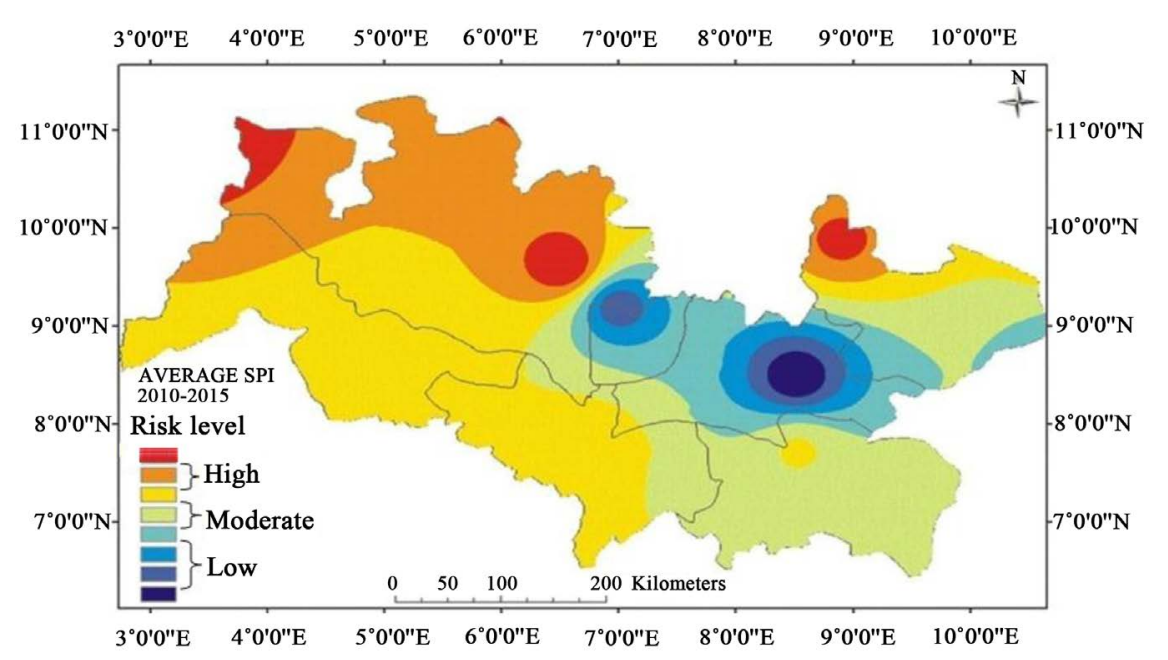

Figure 11. Drought vulnerability map 2010-2015.

The 2010-2015 drought vulnerability map as shown in Figure 11 indicate that the North western, southern and north eastern parts of the region constitute the drought occurring zones as the area is characterize by high drought risk. The reasons adduced for the increasing vulnerability of drought in the aforementioned regions are increasing latitude, declining rainfall and climate change.

\section{Summary and Conclusion}

\section{Rainfall Variability}

The study concludes that spatiotemporal variation in rainfall exists in the study area. The pattern of rainfall variation reveals that all the states in the study area except Abuja were distinct throughout the study period. This variability further explains the vulnerability and occurrence of drought in the region. The observed variability is expected to intensify in the future, given the current climate change projection.

\section{SPI and Drought Vulnerability}

Results of the 12 months SPI model were effective in detecting areas in the north central region that is more vulnerable to the incidence of drought and trend of occurrence. The summary analysis reveals that the northwestern part of the region has been ravaged by drought in the past and remains increasingly vulnerable to the risk of drought. Furthermore, drought vulnerability mapping using SPI can help in initiating local adaptation strategies in order to mitigate the adverse impact of the hazard on the populace in view of the changing nature of the climate.

\section{Recommendation}

The following recommendations will help mitigate the impact of drought in the study area.

1) Development of SPI weather index base insurance: This is innovative as it will improve on farmer's capacity to manage climate shock such as drought. 
2) Development of irrigation and dry season farming.

3) Provision of drought tolerant crops.

4) Expansion of the mandates of the state emergency management agencies to accommodate drought hazards in the respective drought vulnerability areas.

5) Improve drought awareness and knowledge management in the region.

\section{Conflicts of Interest}

The authors declare no conflict of interest.

\section{References}

[1] WMO (2012) WMO Statement on the Status of the Global Climate in 2012. World Meteorological Organization (WMO), Geneva, 2.

[2] Salerno, M.Y. (2015) Assessing the Predictability of Weekly Drought Improvement Using NEBRASKA's Automated Weather Network. M.Sc. Thesis, Department of Atmospheric Science, University of Creighton, Omaha.

[3] Olaniran, O.J. (2002) Rainfall Anomalies: The Contemporary Understanding. 55th Inaugural Lecture Series, University of Ilorin, Ilorin.

[4] Atedhor, G.O. (2016) Growing Season Rainfall Trends and Drought Intensities in the Sudando-Sahelian Region of Nigeria. Faculty Journal of Environment, 8, 41-52.

[5] NIMET (2011) Seasonal Rainfall Prediction (SPR). A Publication of the Nigerian Meteorological Agency Abuja.

[6] NIMET (2017) Seasonl Rainfall Prediction (SPR). A Publication of the Nigerian Meteorological Agency, Abuja.

[7] NIMET (2018) Seasonal Rainfall Prediction (SPR). A Publication of the Nigerian Meteorological Agency, Abuja.

[8] Anufurom, C.A (2009) Climate Change Impacts in Different Agro-Ecological Zones of West Africa. 30th International Post Graduate Course at the Regional WMO Training Center.

[9] Mamman, J.M. (2018) Effects of Rainfall Trend Yield in Mohua, Niger State, Nigeria. Journal of Environmental Analysis and Ecology Studies, 1, Article ID: 000512.

[10] Farauta, B.K., Egbule, C.L., Idrisa, Y.L. and Agu, C.V. (2011) Climate Change and Adaptation Measures in Northern Nigeria: Empirical Situation and Policy Implications. The African Technology Policy Study Network, Nairobi.

[11] Mohammed, S. and Abdullahi, U. (2015) Analysis of Periodic Drought and Daptative Strategies of Smaller Farming Communities in Dawakin Tofa and Rimi Drylands of Northwestern Nigeria. In: Proceedings of the 1 st International Conference on Drylands, Centre for Dry land Agriculture, Kano.

[12] Utser, J.T. and Aho, M.I. (2012) Water Shortage and Health Problems in Benue State Nigeria. Impacts and Prospects for Solutions. International Journal of Scientific and Technology Research, 1, 79-85.

[13] Aper, J.A. (2006) Stream Discharge Characteristics in the Lower Benue Drainage Basin. PhD Thesis, the School of Graduate Studies, University of Nigeria, Nsukka.

[14] Oladipo, E.O. (1993) A Comprehensive Approach to Drought and Desertification in Northern Nigeria. Natural Hazards, 8, 235-261. https://doi.org/10.1007/BF00690910

[15] Mckee, T.B., Doesken, N.J. and Kleist, J. (1993) The Relationship of Drought Frequency and Duration to Time Scales. In: Proceedings of the 8 th Conference on Ap- 
plied Climatology, Vol. 17, American Meteorological Society, Anaheim, 179-183.

[16] Nigeria Meteorological Agency (2018) Released Rainfall Data for Academic Research, Headquarters, Abuja Nigeria.

[17] Binboll, N.L. and Edicha, J.A. (2012) Drought Risk Assessment in Yola, Adamawa State Nigeria. Katsina Journal of Natural and Applied Sciences, 2.

[18] Fabeku, B.B. and Okogbue, E.C. (2014) Trends in Vegetation Response to Drought in Sudano-Sahelian Part of Northern Nigeria. Journal of Atmospheric and Climate Sciences, 4, 569-588. https://doi.org/10.4236/acs.2014.44052

[19] Alatise, M.O. and Ikumawoyi, O.B. (2007) Evaluation of Drought from Rainfall Data for Lokoja. A Confluence of Two Major Rivers. Electronic Journal of Polish Agricultural Universities, 10, Article ID: \#05.

[20] Achugbu, I.C. and Anugwo, S.C. (2016) Drought Trend Analysis in Kano Using Standardized Precipitation Index. Journal of Engineering and Technology, 1, 105-110.

[21] Okpara, J.N., Tarbule, A. and Perumal, M. (2013) Study of Climate Change in Niger River Basin. West Africa Reality Not a Myth. In: Singh, B.R., Ed., Climate Change Realities over Ice Caps, Sea Level and Risk in Tech Rijeka, IntechOpen, London.

[22] Olajuyibe, A.E., Adegboyega, S. and Balogun, I. (2016) Monitoring Drought and Effects on Vegetation in Sokoto, Nigeria Using Statistical and Geospatial Technologies. Ethiopian Journal of Environmental Studies and Management, 9, 56-59. https://doi.org/10.4314/ejesm.v9i1.6

[23] Ideki, O. (2018) Vulnerability and Adaptation Strategies to Drought Risk in North Central Nigeria. Unpublished Ph.D Thesis, School of Graduate Studies, University of Port Harcourt, Port Harcourt. 